\title{
Outcome Measurement for Orthopaedic Trauma Inpatients
}

\begin{abstract}
In clinical physiotherapy, there is growing importance for the accuracy and reliability of assessment and outcome measures. There are no outcome measure instruments for orthopaedic trauma inpatients published in the literature. This paper reports on the initial research to develop an outcome measure for orthopaedic trauma inpatients. Item generation was done by doing a systematic review of published functional outcome measures. Item reduction was conducted by using a panel of physiotherapists and patients. A total of 115 functional items were generated and this was reduced to 29 functional items deemed appropriate for othopaedic trauma inpatients. Although further

Moghazy E, BSc. 2002'; Louw Q, PhD'

${ }^{1}$ Division of Physiotherapy, Faculty of Health Sciences, Stellenbosch University, Tygerberg, South Africa psychometric properties should now be tested, the draft outcome measure can serve as a guide in the education of undergraduate students as well as to clinicians working in orthopedic trauma wards.
\end{abstract}

KEYWORDS : OUTCOME MEASURES, ORTHOPAEDIC TRAUMA INPATIENTS, PSYCHOMETRIC PROPERTIES.

\section{INTRODUCTION}

In clinical physiotherapy, there is growing importance for the accuracy and reliability of assessment and outcome measures (Horner and Lamer 2006). Measuring outcomes is believed to improve the reliability with which we monitor progress and this may enhance patient management. Outcome measures developed over the past two decades are now well recognized as an integral component of patient assessment and monitoring (Horner and Lamer 2006). Self-reported outcome measures allow the opportunity for patients to report on their perspective of their performance and progress (Gabel et al 2006). Such information is critical in planning management programs and is often regarded as a more reliable indicator of the patient's performance than impairment measures such as pain or range of movement.

Internationally, physiotherapy professional bodies are actively involved in promoting the use of outcome measures, although a recent study indicated that outcome measures are still underutilized by physiotherapists in South Africa (Inglis et al 2008). In South-Africa, there is a dire need to promote the use of outcome measures as there is increased pressure to demonstrate our effective- ness to government and private health funders (Inglis et al 2008). Clinicians should therefore at least monitor patient progress using the most appropriate outcome measures which will reflect on the effectiveness of an intervention as well as the patient's perspectives about the intervention and outcomes (O'Sullivan and Schmitz 1994). The most appropriate outcome measure is usually a simple, inexpensive and efficient mechanism for collecting standard information routinely for a specific patient population (Donnelly and Carswell 2002). A range of outcome measures are now available for different patient populations commonly treated by physiotherapists. However, the majority of outcome measures have been developed and validated for orthopaedic outpatient populations (Williams et al 2007). While orthopedic outpatients arguably form the largest patient population for physiotherapy practice in South Africa, other prevalent patient populations treated by physiotherapists desperately need measure for outcome of intervention.

In South Africa, trauma is the fourth most common health burden (Inglis et al 2008), and therefore trauma inpatients constitute a significant proportion of patients treated by local physiotherapists. Traumatic neuro-musculoskeletal dis- orders are defined as acute orthopaedic trauma conditions. This includes fractures and dislocations as well as severe soft tissue injuries caused by traumatic events. No valid outcome measure could be found in the literature for trauma inpatients to monitor and assess progress in this field. Outcome measures currently available may be too generic and not sensitive enough to detect change over time in trauma inpatients (Grimmer et al 2005). This paper reports on the initial steps taken to develop an outcome measure for trauma inpatients which can be useful in monitoring improvement and discharge planning. The aim of this project was to conduct the initial research towards development of a measurement tool for outcomes in orthopaedic trauma inpatients.

\section{Correspondence to:}

Quinette Louw

Division of Physiotherapy,

Faculty of Health Sciences,

Stellenbosch University,

PO Box 19063,

Tygerberg

78505 ,

South Africa

Tel: +27219389301

Email: qalouw@sun.ac.za 


\section{METHODOLOGY}

The first objective of the study was to conduct item generation for a draft outcome measure for trauma inpatients by doing a systematic review of the relevant published literature. Secondly, item reduction was achieved by using the opinions of an appropriate group of physiotherapists and patients.

\section{Item generation}

The review of the literature was conducted in September 2007. Thirteen databases including Pubmed, Proquest, Science Direct, Cochrane Library, Web of Science, Ebschohost, Journals Ovid, Psycho info, Sport Discus, Pedro, Cinahl, Scirus, and Biomed Central were searched. We sought descriptive studies that included studies describing the development process, scoring methods and contents of physical functional self report outcome measures used in adults with traumatic neuromusculoskeletal disorders. Only papers published in Arabic or English and presented in full-text format were accepted. No limit was set on the publication date. The participants included male and female adults aged above 19 years. The psychometric properties of the physical function self-report outcome measures of activity limitations in adults were also evaluated.

The search terms and strategies included "physical function", "self-report outcome measures", "psychometric properties" and "activity limitation". The eligibility criteria were applied by two independent reviewers. All the possible hits were initially screened by the primary reviewer. Thereafter, full text screening was done by two reviewers. The reference lists of the eligible articles were then screened for more potential research reports to include. The full text papers were retrieved to make final decisions about inclusion of papers.

\section{Data extraction and methodological scoring}

In order to provide a clear description of each study, specific data was extracted from each retained article based on standard data extraction forms for systematic reviews. The headings were validated by the secondary reviewer and all extracted data was stored on a Microsoft Excel database.

\section{Methodological quality appraisal}

We used a checklist, modified by Williams et al (2007), to appraise the development method of the measures. The psychometric properties of the identified measures were evaluated based on the following criteria: (1) content validity; (2) construct validity; (3) internal consistency; (4) test-retest reliability; (5) responsiveness; (6) respondent burden and (7) administrative burden.

Scoring was conducted as follows: a) "+" which was given a value of 1.0 , indicated that adequate methods and results were used ; b) ' \pm ', which was given a value of 0.5 , demonstrated that doubtful methods and results were used; c) "'." was given a value of 0.0 , indicated that inadequate methods and results were used, and d) "?'" which was given a value of 0.0 showed that no information was found. The highest possible score that an instrument could achieve was 7.0 (see Table1).

Item reduction was conducted by using five physiotherapists with at least five years working experience in an orthopaedic trauma ward, and ten trauma inpatients. This panel was instructed to independently review the list of 115 functional items generated during the review process and indicate which they deem most appropriate for trauma inpatients. The reduction of items was done by the frequency with which a specific item was deemed appropriate and relevant to trauma inpatients population by all members of the panel. The items were thus reduced by selection of items nominated by all members of the panel. The patient group was also used to review the scoring methods and propose the reporting method they find most appropriate and easy to understand.

\section{RESULTS}

Eight articles were considered eligible for this review (see figure 1). These articles reported on the Upper Limb Functional Index (ULFI) (Gabel et al 2006), Functional Independence Measure (FIM) (Jette et al 2005), Functional Independence Staying (FIS) (Jette et al 2005), Activity Measure for Post Acute
Care (AM-PAC) (Haley et al 2004), Barthel Index (BI) (Hobart and Thompson 2001), Lower Extremity Functional Scale (LEFS) (Binkley et al 1999), Patient Specific Functional Scale (PSFS) (Chatman et al 1997), Functional Independence Measure (FIM) (Dodds et al 1993). The eligible papers were published between 1993 and 2006, and the studies were conducted in the USA (4), Canada (2), United Kingdom (1), and Australia (1).

The sample size in the selected studies ranged from $n=38$ (Chatman et al 1997) to $n=11102$ (Dodds et al 1993). The larger studies were conducted in USA. The mean age of the participants was 47 years, although one article did not provide the age of the subjects (Jette et al 2005). Six of the eight articles indicated that both male and female participated in the included studies. Two studies did not mention the gender (Gabel et al 2006, Jette et al 2005).

\section{Critical appraisal of the quality of the outcome measurement tools used in eligible studies}

Of the eight studies that met the eligibility criteria, five instruments achieved a score of 4.0 or higher. Overall, the highest quality ratings were given to the Gabel et al 2006 and Binkley et al 1999 (6.0 out of 0.7). Chatman et al 1997 were received (5.5 out of 7.0), and Hobart and Thompson 2001 given (5.0 out of 7.0). Haley et al 2004 (0.4 out of $0.7)$, but Jette et al 2005a; Jette et al 2005b and Dodds et al 1993 achieved a quality rating of $2.5,2.5$ and 2.0 out of 7.0 (Table1).

A total of 104 functional activity items were generated from the eight published scales. These are summarized it in Table 2. A range of functional activities have been covered, including many activities related to occupational or sporting activity, which were potentially not appropriate for trauma inpatients.

\section{Draft functional items for trauma inpatient outcome measure (see table 3)}

The list of functional outcome items generated from the published studies was reduced to 21 function activity items after removing the duplicates and 


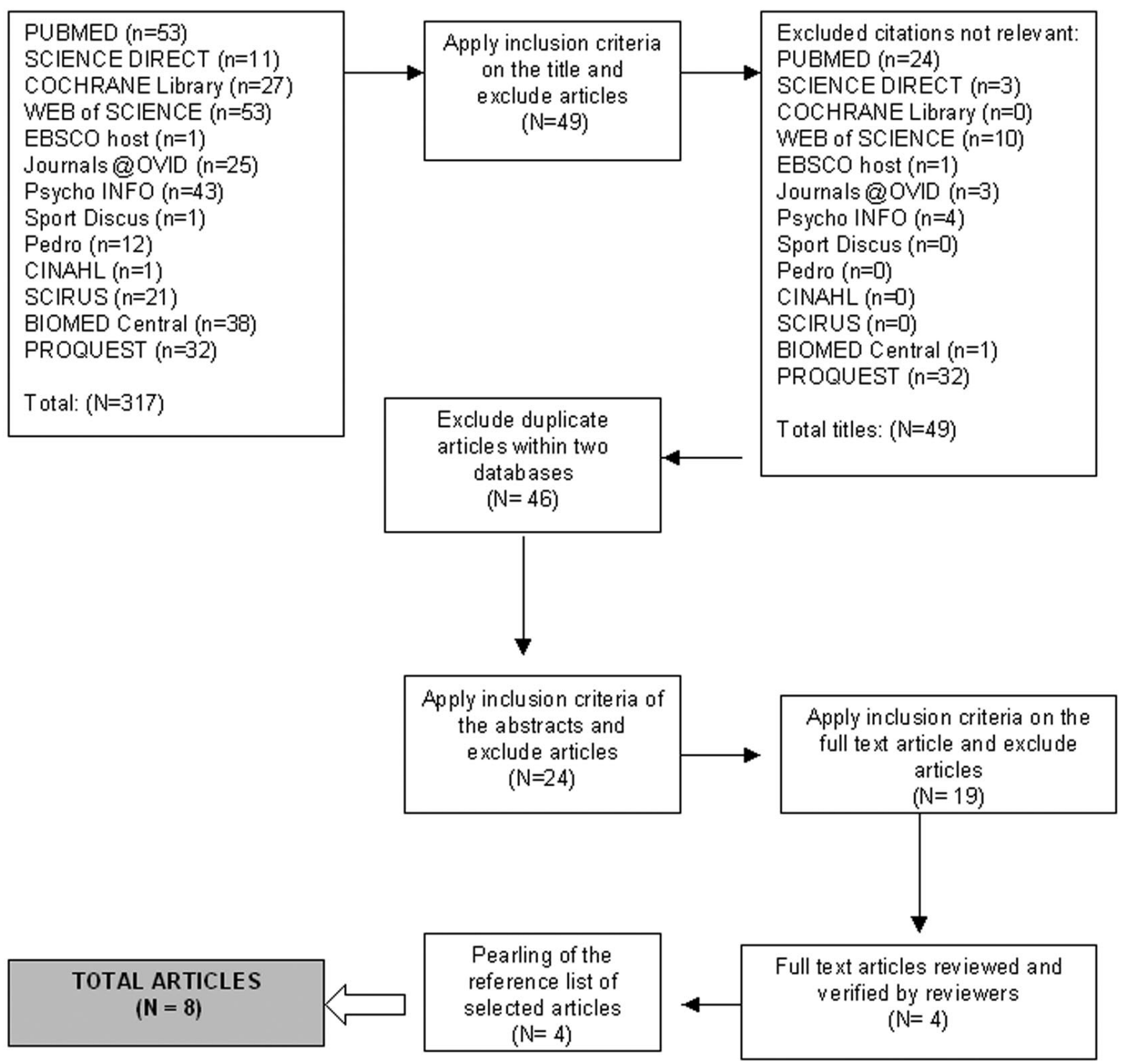

after the physiotherapists and patient panel reviewed the items. We categorized the items according to the International Classification of Function (ICF) specifically to three functional categories (bed-activities, out of bed activities and ADL's). We have also proposed a scoring method based on review of the published functional outcome measures as well as patient reviews. The proposed scoring is 0 (independent), 1 (minor help), 2 (major help) and 3(unable) and this is based on the functional scales included in the review. The best score in the proposed questionnaire is thus 0 and the worst score 87 .

\section{DISCUSSION}

A review of the literature demonstrated that there is very limited information available on the outcome assessment for inpatients. Trauma orthopaedic inpatients present one subgroup of hospital inpatients, but this review highlights the limitations in measuring the function of 


\begin{tabular}{|c|c|c|c|c|c|c|c|c|c|}
\hline Authors & 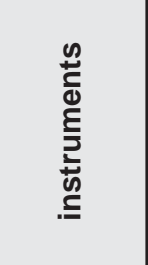 & 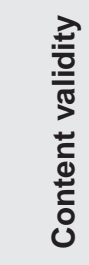 & 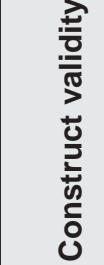 & 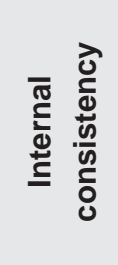 & 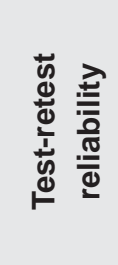 & 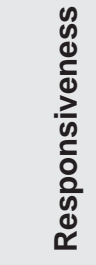 & 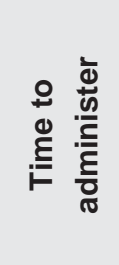 & 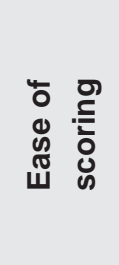 & $\begin{array}{l}\frac{0}{3} \\
\frac{1}{\pi} \\
\frac{0}{\pi}\end{array}$ \\
\hline Gabel et al 2006 & ULFI & $\begin{array}{l}+ \\
1.0\end{array}$ & $\begin{array}{l}+ \\
1.0\end{array}$ & $\begin{array}{l} \pm \\
0.5\end{array}$ & $\begin{array}{l}+ \\
1.0\end{array}$ & $\begin{array}{l}+ \\
1.0\end{array}$ & $\begin{array}{l}+ \\
1.0\end{array}$ & $\begin{array}{l} \pm \\
0.5\end{array}$ & 6.0 \\
\hline Jette et al 2005a & FIM & $\begin{array}{l}? \\
0.0\end{array}$ & $\begin{array}{l}+ \\
1.0\end{array}$ & $\begin{array}{l}+ \\
1.0\end{array}$ & $\begin{array}{l}? \\
0.0\end{array}$ & $\begin{array}{l}? \\
0.0\end{array}$ & $\begin{array}{l}? \\
0.0\end{array}$ & $\begin{array}{l} \pm \\
0.5\end{array}$ & 2.5 \\
\hline Jette et al 2005b & FIS & $\begin{array}{l}? \\
0.0\end{array}$ & $\begin{array}{l}+ \\
1.0 \\
\end{array}$ & $\begin{array}{l}? \\
0.0 \\
\end{array}$ & $\begin{array}{l}? \\
0.0\end{array}$ & $\begin{array}{l}+ \\
1.0 \\
\end{array}$ & $\begin{array}{l}? \\
0.0\end{array}$ & $\begin{array}{l} \pm \\
0.5\end{array}$ & 2.5 \\
\hline Haley et al 2004 & AM-PAC & $\begin{array}{l}+ \\
1.0\end{array}$ & $\begin{array}{l}+ \\
1.0\end{array}$ & $\begin{array}{l}+ \\
1.0\end{array}$ & $\begin{array}{l}? \\
0.0\end{array}$ & $\begin{array}{l}? \\
0.0\end{array}$ & $\begin{array}{l}? \\
0.0\end{array}$ & $\begin{array}{l}+ \\
1.0\end{array}$ & 4.0 \\
\hline Hobart and Thompson 2001 & BI & $\begin{array}{l} \pm \\
0.5\end{array}$ & $\begin{array}{l}+ \\
1.0\end{array}$ & $\begin{array}{l} \pm \\
0.5\end{array}$ & $\begin{array}{l}+ \\
1.0\end{array}$ & $\begin{array}{l}+ \\
1.0\end{array}$ & $\begin{array}{l}? \\
0.0\end{array}$ & $\begin{array}{l}+ \\
1.0\end{array}$ & 5.0 \\
\hline Binkley et al 1999 & LEFS & $\begin{array}{l}+ \\
1.0\end{array}$ & + & $\begin{array}{l}+ \\
1.0\end{array}$ & $\begin{array}{l}+ \\
1.0\end{array}$ & $\begin{array}{l}+ \\
1.0\end{array}$ & $\begin{array}{l}? \\
0.0\end{array}$ & $\begin{array}{l}+ \\
1.0\end{array}$ & 6.0 \\
\hline Chatman et al 1997 & PSFS & $\begin{array}{l}+ \\
1.0\end{array}$ & $\begin{array}{l}+ \\
1.0\end{array}$ & $\begin{array}{l}? \\
0.0\end{array}$ & $\begin{array}{l}+ \\
1.0\end{array}$ & $\begin{array}{l}+ \\
1.0\end{array}$ & $\begin{array}{l}+ \\
1.0\end{array}$ & $\begin{array}{l} \pm \\
0.5\end{array}$ & 5.5 \\
\hline Dodds et al 1993 & FIM & $\begin{array}{l}? \\
0.0\end{array}$ & $\begin{array}{l}+ \\
1.0\end{array}$ & $\begin{array}{l} \pm \\
0.5\end{array}$ & $\begin{array}{l}? \\
0.0\end{array}$ & $\begin{array}{l} \pm \\
0.5\end{array}$ & $\begin{array}{l}? \\
0.0\end{array}$ & $\begin{array}{l}? \\
0.0\end{array}$ & 2.0 \\
\hline
\end{tabular}

PSFS: patient specific functional scale, ULFI: upper limb functional index, FIM: functional independence measure

FIS: functional independence staying, AM-PAC: activity measure for post acute care, BI (PADL): Barthel Index measure of physical dependence in Personal Activities of Daily Living, LEFS: lower extremity functional scale.

(" $+"=1.0$, indicated that adequate methods and results were used, " \pm " $=0.5$, demonstrated that doubtful methods and results were used, "'-" $=0.0$, indicated that inadequate methods and results were used, "'?' $=0.0$, showed that no information was found).

Table 2: Summary of functional items listed in eligible papers

\begin{tabular}{|l|l|}
\hline Scales/ Authors & Items \\
\hline $\begin{array}{l}\text { FIM, Jette et al } 2005 \text { and } \\
\text { FIS, Jette et al } 2005\end{array}$ & ADL, Mobility, Sphincter management and executive function. \\
\hline AM-PAC, Haley et al 2004 & $\begin{array}{l}\text { Applied cognition items ( }=15) \text {, Personal care \&instrumental (N=16 items), } \\
\text { Physical \&movement ( }=10 \text { items) }\end{array}$ \\
\hline $\begin{array}{l}\text { BI, Hobart and } \\
\text { Thompson 2001 }\end{array}$ & $\begin{array}{l}\text { (1) Going up and down stairs, (2) Transferring to and from a toilet, (3) bathing, } \\
\text { (4) Walking on level surface, (5) Transfer from wheel chair to bed and return }\end{array}$ \\
\hline LEFS, Binkely et al 1999 & $\begin{array}{l}\text { Any of your usual work, hobbies, recreational or sporting activities, washing (bath), } \\
\text { walking between rooms, putting on your shoes or socks, squatting, lifting an object, like a } \\
\text { bag of groceries from the floor, light activities around your home, performing heavy } \\
\text { activities around your home, getting into or out of a car, walking, going up or down } \\
10 \text { stairs (about 1 flight of stairs), standing for 1 hour, Sitting for 1 hour, running on } \\
\text { even ground, running on uneven ground, making sharp turns while running fast, } \\
\text { hopping, rolling over in bed. }\end{array}$ \\
\hline
\end{tabular}

many other inpatient populations such as intensive care patients. The availability of a valid and reliable tool to measure functional status of inpatients in conjunction with a structured outcome measurement plan will empower physiotherapists to contribute towards discharge planning (Horner and Lamer 2006). This may be of particular impor- tance in the current economic climate where patients are discharged as soon as possible (Oldmeadow et al 2002) Knowledge of whether the patient has obtained the desired level of function to warrant discharge can assist physiotherapists in making contingency plans for patients at sub-acute health care facilities. If step down facilities are not available, at least caregivers of the patients can be provided with a structured plan of how they can facilitate the functional activities not achieved during the inpatient phase.

The review also highlights factors that may be important to the clinician in the clinical setting and are often not addressed. Only two of the scales tested 
Table 3: Draft functional items for trauma inpatient outcome measure

\begin{tabular}{l}
$\begin{array}{l}\text { A) Of all the activities you are allowed to perform due to your injury, score your ability to } \\
\text { perform the following bed activities. }\end{array}$ \\
\hline 1. Roll over in bed \\
\hline 2. Reach for objects next to bed \\
\hline 3. Shift in bed ( side to side or up and down) \\
\hline 4. Sit up from lying on bed \\
\hline 5. Maintain sitting on bed(e.g., long sitting) \\
\hline 6. Maintain sitting over edge of bed \\
\hline 7. Change position from edge of bed to sitting or lying in bed
\end{tabular}

B) Of all the activities you are allowed to perform out of bed due to your injury, score your ability to perform the following OUT of bed activities.

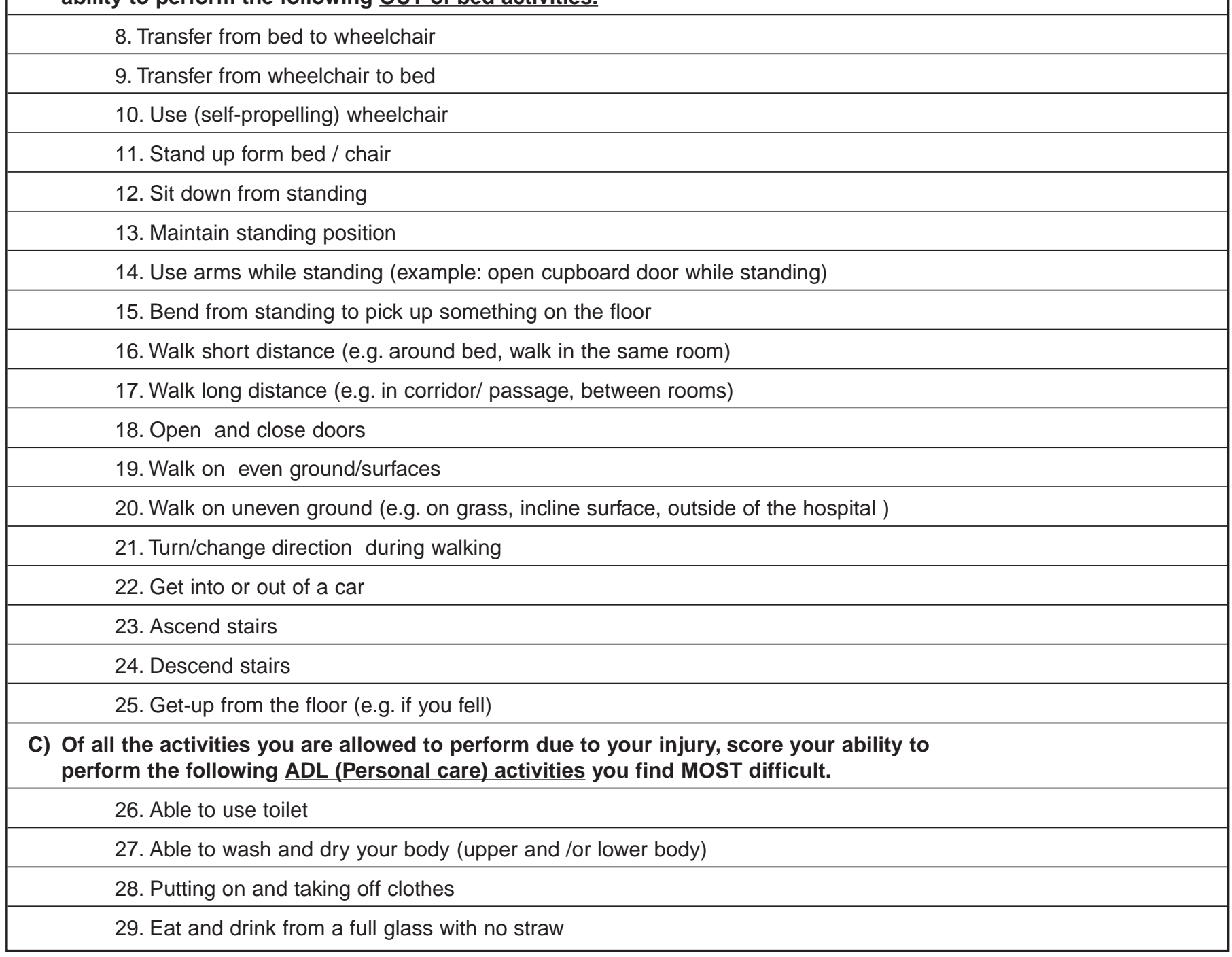

"time to administer" and this is of concern as this administrative burden can be barrier to the use of outcome measures in clinical practice. As the use of outcome measures still requires facilitation among South African physiotherapists (Inglis et al 2008), researchers developing new outcome measures should attempt to minimize the barriers associated with the regular application of outcome measures in clinical practice. This will hopefully facilitate an increase in the uptake of outcome measurements in clinical practice.

The need of a specific tool for trauma inpatients is also highlighted by the large range of functional activities generated in this study which are not appropriate for inpatients. The majority items and scoring methods of published functional scales were not appropriate for trauma inpatients. A total of 104 functional items were generated and this was reduced to 29 items, deemed to be appropriate by a clinical and patient panel. This paper illustrates that an appropriate physiotherapists panel and patient group may be a useful methodological approach to reduce functional activities in order to customize an outcome measure for a specific patient population. However, further review by knowledgeable experts, including testing of psychometric properties should be incorporated in the next phase of development (Grimmer et al 2005). 


\section{CONCLUSION}

This paper reports on the first steps undertaken to develop of an outcome measure for othopaedic trauma inpatients, motivated by the fact that no publication of such measure could be found. Although these are preliminary steps, the draft outcome can serve as a guide in the education of undergraduate students as well as to clinicians working in orthopedic trauma wards.

\section{ACKNOWLEDGEMENTS}

My special gratitude goes to Professor Quinette Louw whose encouragement and ardent support was present throughout my study. We also thank Professor Paul Stratford (PSFS developer) who provided feedback on the first draft of this manuscript.

\section{REFERENCES}

Australian Physiotherapy Association 2003last update, Cinical Justification and Outcome Measures [Homepage of APA 2003], [Online]. Available: http://apa.advsol.com.au/independent/documents/position_statements/public/C inicalJustification\&Outcome\%20Measures.pdf.

Binkley J.M., Stratford P.W., Lott S.A. \& Riddle D.L. 1999, "The Lower Extremity Functional Scale (LES): Scale Development, Measurement Properties, and Cinical Application", PHYSICAL THERAPY, vol. 79, no. 4, pp. 371-383.

Chatman A.B., Hyams S.P., Neel J.M., Binkley J.M., Stratford P.W., Schomberg, A. \& Stabler, M. 1997, "The Patient-Specific Functional Scale: Measurement Properties in Patients With Knee Dysfunction", PHYSICAL THERAPY, vol. 77, no. 8, pp. 820-829.
Dodds TA, Martin DP, Stolov WC \& Deyo RA 1993, "A validation of the functional independence measurement and its performance among rehabilitation inpatients.", ARCHIVES OF PHYSICAL MEDICINE AND REUABILITATION, vol. 74, no. 5, pp. 531-6.

Donnelly C \& Carswell A. 2002, "Individualized outcome measures: A review of the literature", CANADIAN JOURNAL OF OCCUPATIONAL THERAPY, vol. 69, pp. 84-94.

Gabel C.P., Michener L.A., Burkett B. \& Neller A. 2006, "The Upper Limb Functional Index: Development and Determination of Reliability, Validity, and Responsiveness", JOURNAL OF HAND THERAPY, vol. 19, no. 3, pp. 328-349.

Haley S, Coster W, Andres P, Ludlow L, Ni P, Bond T, Sinclair S and Jette A, 2004, Activity Outcome Measurement for Postacute Care. [Homepage of Medical Care, Vol. 42(1), January 2004, pp. I-49], [Online]. Available: http://www.luw-medicalcare.com.

Hobart J.C. \& Thompson A.J. 2001, "The five item Barthel index", JOURNAL OF NEUROLOGY, NEUROSURGERY AND PSYCHIATRY, vol. 71, pp. 225-230.

Horner D. \& Larmer P.J. 2006, "Health outcome measures", New Zealand Journal of physiotherapy., vol. 34, no. 1, pp. 17-24.

Inglis G, Faure M, Frieg A. 2008. The Awareness and Use of Outcome Measures by South African Physiotherapists Authors. SOUTH AFRICAN JOURNAL OF PHYSIO THERAPY vol. 64, no. 2, pp 5-12

Jette D.U., Warren R.L. \& Wirtalla C. 2005,(a) "Functional Independence Domains in Patients Receiving Rehabilitation in Skilled Nursing Facilities: Evaluation of Psychometric Properties", ARCHIVES OF PHYSICAL MEDICINE AND REUABILITATION, vol. 86, no. 6, pp. 1089-1094.
Jette D.U., Warren R.L. \& Wirtalla C. 2005 , (b) "Validity of Functional Independence Staging in Patients Receiving Rehabilitation in Skilled Nursing Facilities", ARCHIVES OF PHYSICAL MEDICINE AND REHABILITATION, vol. 86, no. 6, pp. 1095-1101.

Odmeadow L.B., McBurney H. \& Robertson V.J. 2002, "Hospital stay and discharge outcomes after knee arthroplasty: Implications for physiotherapy practice", AUSTRALIAN JOURNAL OF PHYSIOTHERAPY, vol. 48, pp. 117-121.

OSullivan S.B. \& Schmitz T.J. 1994, Physical rehabilitation: assessment and treatment, F.A. Davis, Philadelphia.

Williams R.M., Schmuck G, Allwood S., Sanchez M., Shea R. \& Wark G. 2007, "Psychometric Evaluation of Health-Related Work Outcome Measures For Musculoskeletal Disorders: A Systematic Review", JOURNAL OF OCOUPATIONAL REHABILITATION, vol. 17, no. 3, pp. 504-521. 